\title{
Synthesis of Carbon Core-Shell Pore Structures and their Performance as \\ Supercapacitors
}

Teguh Ariyanto ${ }^{\mathrm{a}}$, Boris Dyatkin ${ }^{\mathrm{b}}$, Gui-Rong Zhang ${ }^{\mathrm{a}}$, Andreas Kern ${ }^{\mathrm{a}}$, Yury Gogotsi ${ }^{\mathrm{b}}$, Bastian J.M. Etzold ${ }^{\text {a* }}$

${ }^{a}$ Lehrstuhl für Chemische Reaktionstechnik, Friedrich-Alexander-Universität ErlangenNürnberg, Egerlandstrasse 3, 91058 Erlangen, Germany

${ }^{b}$ Department of Materials Science \& Engineering, and A.J. Drexel Nanomaterials Institute, Drexel University, Philadelphia, PA 19104, USA

*Corresponding authors. Tel.: +49 91318527430 . Fax: +4991318527421.

E-mail: bastian.etzold@fau.de 


\begin{abstract}
High-power supercapacitors require excellent electrolyte mobility within the pore network and high electrical conductivity for maximum capacitance and efficiency. Achieving high power typically requires sacrificing energy densities, as the latter demands a high specific surface area and narrow porosity that impedes ion transport. We present a novel solution for this optimization problem: a nanustructured core-shell carbonaceous material that exhibits a microporous carbon core surrounded by a mesoporous, graphitic shell. Our tunable synthesis parameters yielded a structure that features either a sharp or a gradual transition between the core and shell sections. Electrochemical supercapacitor testing using organic electrolyte revealed that these novel core-shell materials outperform carbons with homogeneous pore structures. The hybrid core-shell materials showed a combination of good capacitance retention, typical for the carbon present in the shell and high specific capacitance, typical for the core material. These materials achieved power densities in excess of $40 \mathrm{~kW} \mathrm{~kg}^{-1}$ at energy densities reaching $27 \mathrm{Wh} \mathrm{kg}^{-1}$.
\end{abstract}

Keywords: core-shell pore structures, carbide-derived carbons, supercapacitors, power density 


\section{Introduction}

Electrochemical capacitors, also called supercapacitors, are attracting wide attention as energy storage devices. Compared to batteries and conventional capacitors, they present a unique balance between energy and power densities [1-3]. Supercapacitors exhibit high power densities that give them a performance advantage in applications including hybrid electrical vehicles, pulsed laser systems, solar-powered streetlights, and power tools $[1,4,5]$. This rapid charge/discharge capability is influenced by rate of ion electrosorption and transport through pores, which is especially inhibited at low operation temperatures [6], as well as electrical conductivity of electrodes. Although mesoporous materials feature greater ion mobilities and capacitance retention than microporous carbons, they exhibit lower specific surface areas and, subsequently, limited energy densities [7]. Although ions achieve optimal desolvation and packing densities in systems with matching ion-pore diameters [8], microporous electrodes often inhibit ion transport and reduce rate handling abilities [9]. Recent research efforts have introduced external surface structures, e.g. onion-like carbons [10] or, carbon hollow spheres [11] approaches to enhance power densities. However, these alternatives still exhibit low specific surface areas and limited charge storage capabilities. Therefore, an optimal material for supercapacitor electrodes must provide an appropriate balance between the properties needed for high energy density and the ones necessary for rate handling capability and high electrical conductivity [12-14].

Hierarchically structured materials can fulfill these demand and require i) prevalence of micropores to maintain high capacitance, ii) network of mesopores to facilitate rapid ion transport, and iii) direct introduction of graphitic structures to improve electrical conductivity. In this work, we introduce a novel synthesis methodology that enables the production of innovative porous carbons that features a mesoporous/graphitic shell (allowing both fast ion transport and high electric conductivity) that envelops a microporous core that features a high specific surface area. The schematic of this core-shell electrode structure is illustrated in Fig. 
1. We demonstrate that structural advantages that step from this novel synthesis approach enhance electrochemical capacitor the power density by a factor of 1.7 without noticeably decreasing either the gravimetric or volumetric energy densities.

The desired structures were synthesized by chemically etching TiC carbide precursors, yielding a carbonaceous material (CDC) with a high specific surface area and tunable porosity [15]. Briefly, CDC can be produced by reactive extraction of metals from carbides using chlorine gas at high temperatures, with the precursor and synthesis temperature governing the resulting porosity and degree of graphitization [16-20]. This process is characterized by the temperature influence on the structure of the resulting CDC and the shrinking core reaction mechanism (SCM), hence, the conversion of the material from the outside towards the center during selective extraction $[21,22]$. We took advantage of accessible pore diameters $(0.6-1.5$ $\mathrm{nm}$ ) of TiC-CDC produced by $\mathrm{Cl}_{2}$ etching in the $400-1200{ }^{\circ} \mathrm{C}$ temperature range $[23,24]$. Furthermore, since conversion follows SCM, a partially chlorinated carbide particle is likely to feature a CDC shell covering a carbide core $[25,26]$. Based on this knowledge, we propose a novel $\mathrm{CDC}$ synthesis procedure that relies on two-stage $\mathrm{Cl}_{2}$ etching to produce core-shell particles with different pore sizes and carbon microstructures on the surface and in the core. Results of two different routes of this non-isothermal CDC synthesis, using non-porous, commercially available TiC precursors, are presented in this work. The first route is the partial conversion of the carbide at a constant temperature, which determines the pore size distribution and graphitic character of the CDC shell. Following an inert gas flushing step, the remaining carbide core is converted at a different temperature and, subsequently, features a different average pore size. This approach yields a sharp microstructure transition between the core and shell architectures (materials will be labeled as "CDC-STEP"). The second route implements a constant temperature ramp between two distinct temperatures, resulting in a gradual change of the pore structure and graphitic character (materials henceforth labeled as "CDC-GRADUAL"). Both approaches depend on careful control of synthesis temperature 
and time steps and generate distinct porosities and divergent pore architectures in the outer and inner parts of the carbon particles.

To avoid heterogeneous structures in the powder bed (particles' properties are largely governed by their location in the reactor), we adjusted the reaction system to facilitate convection and minimize mass transfer limitations. We achieved this by replacing the standard horizontal powder-filled crucible configuration with a quartz glass frit in the middle of a vertical tube reactor and feeding the gaseous reactant from the top (see Fig. S1 in the Supporting Information (SI)).

\section{Experimental}

\subsection{Preparation}

Core-shell materials were synthesized by reactive extraction of $\mathrm{Ti}$ from non-porous commercial TiC (99.5\%, typically $2 \mu \mathrm{m}$, Alfa Aesar) in a vertical quartz tubular reactor $\left(d_{i}=\right.$ $0.034 \mathrm{~m}, l=1 \mathrm{~m}$ ) by using chlorine (purity 2.8, Linde AG) as extraction agent diluted in helium (purity 4.6, Linde AG). For route 1, a CDC shell on a carbide core was produced by reactive extraction of $0.5 \mathrm{~g}$ of $\mathrm{TiC}$ powder at $1200{ }^{\circ} \mathrm{C}$ for $15 \mathrm{~min}\left(0.5 \mathrm{~mol} \mathrm{~m}{ }^{-3} \mathrm{Cl}_{2}\right.$, superficial velocity of $0.015 \mathrm{~m} \mathrm{~s}^{-1}$ ). The interim product in route 1 is denominated as CDC-1200-35\%. After flushing with helium (argon or another inert gas can be used), the reactor was cooled down to $800{ }^{\circ} \mathrm{C}$ and the reactive extraction continued at this temperature for $150 \mathrm{~min}$ at the same $\mathrm{Cl}_{2}$ concentration and superficial velocity (final product: CDC-STEP). For route 2 (CDC-GRADUAL synthesis), a cooling ramp $\left(1200{ }^{\circ} \mathrm{C}\right.$ to $\left.800{ }^{\circ} \mathrm{C}\right)$ at $10{ }^{\circ} \mathrm{C} \mathrm{min}^{-1}$ was started after heating to $1200{ }^{\circ} \mathrm{C}$ and while adding $\mathrm{Cl}_{2}\left(0.5 \mathrm{~mol} \mathrm{~m}^{-3} \mathrm{Cl}_{2}\right.$, flow velocity of $\left.0.015 \mathrm{~m} \mathrm{~s}^{-1}\right)$. To ensure full conversion after reaching $800{ }^{\circ} \mathrm{C}$, the material was chlorinated for $150 \mathrm{~min}$ at constant temperature. The final product of route 2 is denominated as CDC-GRADUAL. For both routes, a hydrogen annealing step was completed at $800{ }^{\circ} \mathrm{C}$ after chlorination to remove residual $\mathrm{Cl}_{2}$ and metal chlorides. To produce reference materials, a standard chlorination procedure was performed at an isothermal reaction temperature at 800 or $1200{ }^{\circ} \mathrm{C}$ until 
obtaining a full conversion as described elsewhere [26] (these materials are labeled, respectively, as “CDC-800" and "CDC-1200").

\subsection{Characterization}

Pore structure of materials was characterized by $\mathrm{N}_{2}$ sorption at $-196{ }^{\circ} \mathrm{C}$ using liquid nitrogen as coolant (Quantrachrome Quadrasorb Si-MP). The pore size distribution was calculated by Quenched Solid State Density Functional Theory (QSDFT) assuming slitshaped pores [27]. A Philips CM300 UT operated at an accelerating voltage of $300 \mathrm{kV}$ was employed for HRTEM. The scanning electron microscopy (SEM) was performed using a Zeiss Gemini Ultra 55 at an accelerating voltage of $2 \mathrm{kV}$. Raman spectra were recorded by using Horiba Jobin Yvon HR 800 spectrometer from 600 to $3400 \mathrm{~cm}^{-1}$ with a HeNe laser $(\lambda=$ $633 \mathrm{~nm}$, power $=20 \mathrm{~mW}$ ) at $50 \mathrm{X}$ magnification objective. Deconvolution of the $\mathrm{D}$ and $\mathrm{G}$ bands was carried out by peak fitting with four Laurentzian/Gaussian models [28,29]. X-Ray Diffraction was executed using an Empyrean Series 2 Diffractometer (PANalytical, Netherlands). We used an Empyrean $\mathrm{Cu}$ tube and a Spellman X-Ray Generator (45 kV, 20 $\mathrm{mA}$ power). We conducted reflection mode measurements using a flat stage in the $5-90^{\circ} 2 \theta$ range, using a $0.026^{\circ}$ step size and at a rate of $3.03^{\circ} /$ minute. Temperature-programmed oxidation (TPO) was performed in Netzsch STA 409 PC Luxx. The material was dried at 150 ${ }^{\circ} \mathrm{C}$ for one hour, and then heated from $150{ }^{\circ} \mathrm{C}$ to $800{ }^{\circ} \mathrm{C}$ with ramp rate of $2.5^{\circ} \mathrm{C} \mathrm{min}^{-1}$ under a flow of air. Peak deconvolution of the oxidation peaks in differential thermogravimetric analysis curves was carried out with two peaks fitting with bi-Gaussian models.

\subsection{Electrochemical measurements}

A circular electrode $12 \mathrm{~mm}$ in diameter was prepared by mixing CDC (95 wt.\%) and PTFE binder (5 wt.\%) without other additives. Cells were assembled in symmetrical pouch cell configurations using carbon-coated aluminum as a current collector (Exopak) and polypropylene membrane (Celgard type 3501) as a separator. More details on the electrode preparation and electrochemical testing are available in the Supporting Information. A VMP-3 
Potentiostat (Bio-Logic Inc., France) was used to carry out electrochemical testing in a twoelectrode configuration. A $1.5 \mathrm{M}$ tetraethylammonium tetrafluoroborate $\left(\mathrm{NEt}_{4}-\mathrm{BF}_{4}, \mathrm{Sigma}\right.$ Aldrich) solution in acetonitrile (HPLC grade purity, Alfa-Aesar) was used as electrolyte. Cyclic voltammograms were collected between $0.0-2.5 \mathrm{~V}$ using voltage sweeps ranging from 5 to $5000 \mathrm{mV} \mathrm{s}^{-1}$. Galvanostatic cycling was carried out at current density of $1.0 \mathrm{~A} \mathrm{~g}^{-1}$ between 0.0 and $2.5 \mathrm{~V}$. Electrochemical impedance spectroscopy was performed using a 10 $\mathrm{mV}$ dampening oscillation centered on $0.0 \mathrm{~V}$ (vs. OCP). The frequency range was from 200 $\mathrm{kHz}$ to $10 \mathrm{mHz}$.

\section{Results and discussion}

\subsection{Materials characterization}

For route 1 mass analysis showed a degree of conversion of approx. $35 \%$ for the interim product (CDC-1200-35\%). This material, the final product CDC-STEP, as also the reference materials converted fully at 800 and $1200{ }^{\circ} \mathrm{C}$ were analyzed with $\mathrm{N}_{2}$ sorption analysis. Pore size distributions (PSD) were determined using the Quenched Solid Density Functional Theory (QSDFT) model and are compared in Fig. 2a for PSDs normalized by total pore volumes. Absolute values of textural properties are summarized in Table 1. CDC-800 showcases a specific surface area of $1540 \mathrm{~m}^{2} \mathrm{~g}^{-1}$ and a $0.61 \mathrm{~cm}^{3} \mathrm{~g}^{-1}$ pore volume; subnanometer pores contribute to 87 vol. $\%$ of the latter. CDC-1200 exhibits the lowest surface area and the highest mesopore volume, which agrees with prior results [30]. The normalized PSD of both reference materials differ clearly and CDC-800 shows pores mainly below $1 \mathrm{~nm}$.

For the interim product, where a porous carbon shell produced at $1200{ }^{\circ} \mathrm{C}$ is expected to cover a non-porous carbide core, the normalized PSD is nearly identical to the $1200{ }^{\circ} \mathrm{C}$ reference material. We observed pores in the micropore and mesopore range. Raman spectroscopy - derived comparison of the carbon ordering of the interim product was compared to the fully converted reference material (Fig. S3a in SI). In accordance to 
literature, CDC-1200 shows a more crystalline character compared to the reference material produced at $800{ }^{\circ} \mathrm{C}$, as expressed by the full width at half maximum (FWHM) and the intensity ratio of the $\mathrm{D}$ and $\mathrm{G}$ bands $[15,18]$. The carbon shell of the interim product shows $\mathrm{D}$ and $\mathrm{G}$ bands that closely resemble the reference $\mathrm{CDC}$ material produced at $1200{ }^{\circ} \mathrm{C}$, as highlighted by similarities in the full width at half maximum (FWHM) and the intensity ratio given in the inset (see Table S1 in SI). Thus the first step in route 1, which produces the carbon shell, resulted in the expected pore- and microstructure properties, which are adjusted by the synthesis temperature of this step.

The final core-shell carbon structure (CDC-STEP) resulting for the first route shows a bimodal pore structure as a mixture of the $800{ }^{\circ} \mathrm{C}$ and $1200{ }^{\circ} \mathrm{C}$ pore size distribution (Fig. 2a). Furthermore, the share of pore volume below $1 \mathrm{~nm}$, which was not present in the interim product and thus must stem from the porous carbon core produced at $800{ }^{\circ} \mathrm{C}$, is in agreement with share of core and shell, adjusted by the degree of conversion of the interim product (35 $\%)$. The absolute values of specific surface area of CDC-STEP are given in Table $\mathbf{1}$ and are in between the references. Probing the crystallinity of the final product with Raman and XRD (results see in the Supporting Information, Fig. S3) shows an interim microstructure between the amorphous $800{ }^{\circ} \mathrm{C}$ and more graphitic $1200{ }^{\circ} \mathrm{C}$ reference materials.

To further characterize the stability of the core-shell material produced after route 1 , temperature-programmed oxidation (TPO) was carried out and compared in Fig. $\mathbf{2 b}$ and $\mathbf{S 4}$ to the reference CDC produced by isothermal conversion. The reference materials showcased predominantly unimodal differential mass loss curves, confirming a homogeneous carbon structure. Materials with higher graphitization become more thermally stable and are oxidized at higher temperatures than amorphous CDCs [31,32]. Hence, CDC-1200 demonstrated a higher oxidation onset temperature $\left(595^{\circ} \mathrm{C}\right)$ than $\mathrm{CDC}-800\left(470{ }^{\circ} \mathrm{C}\right)$. The oxidation profiles for CDC-STEP material exhibited two oxidation peaks centered at $530{ }^{\circ} \mathrm{C}$ (Peak I) and 620 ${ }^{\circ} \mathrm{C}$ (Peak II), respectively, since they contain a mixture of carbons produced at $800{ }^{\circ} \mathrm{C}$ in the 
core and at $1200{ }^{\circ} \mathrm{C}$ in the shell. By integrating and comparing the peak area, the content of the low temperature core was estimated to be $74 \mathrm{wt} . \%$ of the entire particle and thus correlates with the achieved $65 \%$ degree of conversion for the second step.

We applied two approaches to confirm the core-shell structure of the material. We evaluated the CDC-STEP product using Transmission Electron Microscopy (TEM). A representative image of a single particle is shown in Fig. 2c. Due to the contrast difference of carbon and carbide, the electron-transparent carbon shell on the remaining carbide core can be observed clearly. Further investigation using HRTEM at the edge of CDC-STEP showcases a similar carbon structure compared to fully converted reference materials synthesized at 1200 ${ }^{\circ} \mathrm{C}$ (CDC-1200) presenting a multi-layer graphitic structure (see Fig. S5a and S5c). In a secondary approach, we oxidized the CDC-STEP material in air at $430{ }^{\circ} \mathrm{C}$ (burning away just the core) and analyzed the (mechanically crushed) hollow shell structures using SEM. Fig. 2d displays a cross-section of a $220 \mathrm{~nm}$ thick cracked shell with a hollow core. Furthermore, the shell thickness correlates to the adjusted $35 \%$ of degree of conversion for particle with $2 \mu \mathrm{m}$ diameter. We are subsequently able to conclude that the stepwise temperature change in route 1 yielded hierarchically structured core-shell carbon materials, and that the carbon pore and microstructure can be controlled by the synthesis temperature.

Since the CDC-GRADUAL resulting from route 2 does not have a distinct border between its core and shell, the material is difficult to characterize using standard approaches. The results from $\mathrm{N}_{2}$-sorption and TPO are compared in Fig. 2a and $\mathbf{2 b}$ for the reference and CDC-STEP materials. Although a mixed pore structure and carbon microstructure is observed for this sample, the boundary between the core and shell of particles is less distinct, when compared to CDC-STEP. The pore size distribution most prominently shows this gradual transformation. In combination with the previous characterization results, this indicates that the pore size decreases from the outer surface towards the center of the particle and the microstructure from graphitic to amorphous. 


\subsection{Electrochemical characterization}

To study the influence of the novel core-shell structure on the electrochemical performance of these materials, flexible, freestanding film electrodes of the core-shell and reference materials were fabricated as described in the experimental section. First insights are obtained by 4-Point probe measurements of these electrodes, which reveal an electrical conductivity 18 times higher for the more graphitic CDC-1200 $\left(2.72 \mathrm{~S} \mathrm{~cm}^{-1}\right)$ when compared to using the amorphous CDC-800 $\left(0.15 \mathrm{~S} \mathrm{~cm}^{-1}\right)$; the results are included in Table 2 . Interestingly, the electrodes fabricated from both novel core-shell materials show a comparable high conductivity of 1.50 and $2.60 \mathrm{~S} \mathrm{~cm}^{-1}$ for CDC-STEP and CDC-GRADUAL, respectively. Thus, the graphitic shell of the hybrid materials allows for a percolation pathway of the electrons and typically occurs in CDCs produced at $1200^{\circ} \mathrm{C}[20]$.

The electrochemical measurements were conducted using a two-electrode configuration with $1.5 \mathrm{M}$ solution of tetraethylammonium tetrafluoroborate $\left(\mathrm{NEt}_{4}-\mathrm{BF}_{4}\right)$ electrolyte dissolved in acetonitrile. The gravimetric capacitances obtained from cyclic voltammograms $(\mathrm{CV})$ at scan rates of 10 and $500 \mathrm{mV} \mathrm{s}^{-1}$ are shown in the Fig. 3a and 3b. Charge/discharge profiles for all samples at $10 \mathrm{mV} \mathrm{s}^{-1}$ yield rectangular $\mathrm{CVs}$ typical of ideal capacitors and show no mass transfer limitations. At this low scan rate, the highest capacitance of $115 \mathrm{~F} \mathrm{~g}^{-1}$ is observed for the reference material CDC-800, due to its high specific surface area. In contrast, the low-SSA CDC-1200 reference material exhibits the lowest capacitance $\left(40 \mathrm{~F} \mathrm{~g} \mathrm{~g}^{-1}\right)$. Both core-shell pore structure materials show capacitances between those two extremes $\left(95 \mathrm{~F} \mathrm{~g}^{-1}\right)$. At the high scan rate of $500 \mathrm{mV} \mathrm{s}^{-1}$, distortion of the $\mathrm{CV}$ curve due to mass transfer limitations becomes obvious for CDC-800, and its capacitance decreases by $45 \%$. Although some deviations from the ideal rectangular shape are observed for all samples, due to the bigger pores, the mass transport limitation is less pronounced and the drop in capacitance is only 15 $\%$ for CDC-1200. Also importantly, the core-shell pore structured materials exhibited only minor mass transfer limitations: the drop in capacitance was around $20 \%$. 
Fig. 3c compares the surface area normalized capacitance in a broad range of scan rates. At low scan rates, the high surface area CDC-800 and both core-shell materials exhibit a similar surface specific capacitance. Hence, the observed minor drop in gravimetric capacitance results mainly from the slightly lower specific surface area of the core-shell materials. CDC-1200 showed a remarkably lower value, which can arise from the different wettability and influence of the pore size [8,33]. With increasing scan rate, the specific capacitance of CDC-800 continuously decreased above $20-50 \mathrm{mV} \mathrm{s}^{-1}$ scan rates. This can be likely attributed to mass transfer limitation and only $70 \%$ of capacitance is retained at the scan rate of $200 \mathrm{mV} \mathrm{s}^{-1}$. CDC-1200 shows the best capacitance retention with only a minor drop about $10 \%$ with increasing scan rates from 5 to $200 \mathrm{mV} \mathrm{s}^{-1}$. Until reaching the $500 \mathrm{mV}$ $\mathrm{s}^{-1}$ scan rate, a plateau with a very low change in capacitance is observable. Both core-shell pore structures show similar charge/discharge profiles, despite the low amount of CDC-1200 in the shell.

The Randles-Sevcik (RS) coefficient (Table S3) was calculated based on CV measurements for the core-shell structure and the reference materials [1]. While CDC-800 shows significant diffusion limitations $(\mathrm{RS}=0.836)$, both core-shell materials exhibit a nearideal capacitive behaviors with RS coefficients approaching 0.920. To further characterize the electrochemical behavior, the galvanostatic charge-discharge cycling was carried out with a current density of $1 \mathrm{~A} \mathrm{~g}^{-1}$; results are shown in Fig. 4a. The voltage vs. time charge-discharge curves exhibit an ideal capacitive behavior and near-100\% coulombic efficiencies. The specific capacitance values calculated from the discharge time are 42 (CDC-1200), 90 (CDCSTEP), 97 (CDC-GRADUAL), and $110 \mathrm{~F} \mathrm{~g}^{-1}$ (CDC-800). This applied current density is more or less comparable with the $\mathrm{CV}$ measurement with the scan rate of $20 \mathrm{mV} \mathrm{s}^{-1}$, thus the equal specific capacitance results. The electrode surface area resistances $\left(\mathrm{R}_{\mathrm{SA}}\right)$ calculated from the ohmic drop occurring at vertex potentials and polarity shifts (see Fig. 4b) are summarized in Table 2. CDC-1200 and the novel core-shell structures show a low resistance 
of about $2 \Omega \mathrm{cm}^{2}$, while CDC-800 exhibits a high resistance of $\sim 4 \Omega \mathrm{cm}^{2}$. These values corroborate previously measured intrinsic conductivities of the electrodes. Therefore, we can conclude that both, the high conductivity of the outer shell and favorable pore structures, contribute to the exceptional power densities of the core-shell materials.

Electrochemical Impedance Spectroscopy (EIS) measurements were carried out to obtain the dynamic responses, and the corresponding Nyquist plots are shown in Fig. 4c. All the materials show vertical straight lines in the low-frequency region, characteristic of purely capacitive behavior with a minimal ionic resistance. Notably, the CDC-GRADUAL features a more vertical curve than the other electrodes, reflecting that it behaves more like an ideal capacitor. In the high frequency region, the plots of CDC-STEP, CDC-GRADUAL and CDC1200 do not exhibit the semi-circular region that is characteristic of interfacial charge-transfer resistance $\left(\mathrm{R}_{\mathrm{ct}}\right)$, highlighting divergent porosities as predominantly responsible for observed electrochemistry differences [34]. In contrast, the Nyquist plot of CDC-800 exhibits a significant semicircle over the high-frequency region, indicative for a high $\mathrm{R}_{\mathrm{ct}}$ between the electrode and current collector. As listed in Table 2, the $\mathrm{R}_{\mathrm{ct}}$ value of CDC-800 is $c a .3$ to 10 times higher than those of the other materials, probably arising from its low graphitization degree and the consequent lower electrical conductivity $\left(0.15 \mathrm{~S} \mathrm{~cm}^{-1}\right)$. The equivalent series resistance (ESR) can be obtained from the intercept of the Nyquist plot. All materials show comparable ESR of about $0.7 \Omega$. The Bode impedance plots show the normalized capacitance response to frequency in Fig. 4d. The relative capacitance order is: CDC-1200 > CDCGRADUAL $\approx$ CDC-STEP > CDC-800, which corroborates the previously discussed scan-rate handling abilities of these materials. The small relaxation time constant ( $2 \mathrm{~s})$ of the core-shell materials clearly shows their fast charge-discharge response.

A Ragone plot (given in Fig. 3d) was used to correlate energy and power densities. Among the materials, CDC-800 shows the highest energy density of $53 \mathrm{Wh} \mathrm{kg}^{-1}$ at power density of $0.4 \mathrm{~kW} \mathrm{~kg}^{-1}$. Due to the poor rate performance, the energy density decreases 
quickly with increasing power density. When CDC-800's power density reaches $20 \mathrm{~kW} \mathrm{~kg}^{-1}$, the energy density drops by $45 \%$. CDC-1200 shows a much lower energy density of $19 \mathrm{Wh}$ $\mathrm{kg}^{-1}$ due to a lower SSA, but it decreases only slightly with increasing power density up to its maximum $30 \mathrm{~kW} \mathrm{~kg}^{-1}$ value, which matched the maximum value achieved for CDC- 800 . Importantly, for the novel core-shell materials the drop in energy density with increasing power density is less steep (from the lowest power density till $20 \mathrm{~kW} \mathrm{~kg}^{-1}$ for CDCGRADUAL $18 \%$, for CDC-STEP $25 \%$ ) compared to CDC-800 (45\%) and more comparable to CDC-1200. CDC-GRADUAL proves to be the best material at the energy density of $39 \mathrm{Wh}$ $\mathrm{kg}^{-1}$ or below, combining excellent power and energy densities. The maximum power density of both core-shell materials is a factor of 1.7 higher than for both reference materials.

\section{Conclusion}

Carbon core-shell materials were successfully synthesized by two routes that employed $\mathrm{Cl}_{2}$ etching of $\mathrm{TiC}$ and precisely controlled the temperature and time conversion steps. Characterization data $\left(\mathrm{N}_{2}\right.$ sorption, Raman spectroscopy, temperature-programmed oxidation, SEM and TEM) highlights the stepwise or gradual transition between the graphitic, mesopores shells and microporous cores of these materials. We demonstrate a high degree of tunability of the shell thickness of these CDCs using temperature control. The temperature applied during shell or core synthesis also tunes the graphitic structure of the different phases of this nanostructure. As a supercapacitor electrode, this novel carbon nano structure showcases an optimal combination of specific surface area, electric conductivity, and mesopore architecture that provides a critical performance advantage. The core-shell structures yield higher capacitance retention (only $6 \%$ capacitance drop associated with a tenfold sweep rate increase). The core-shell supercapacitor electrodes showcase $27 \mathrm{Wh} \mathrm{kg}^{-1}$ energy densities and $40 \mathrm{~kW} \mathrm{~kg}^{-1}$ power densities. In addition to energy storage systems, the beneficial pore and graphitic structure of these materials is highly applicable in applications such as electrocatalysis, thermal catalysis and gas or liquid phase sorption. 


\section{Acknowledgments}

T.A., G.Z., A.K. and B.E. gratefully acknowledge the funding of the German Federal Ministry of Education and Research (BMBF) under the project AktivCAPs and the German Research Council (DFG), which, within the framework of its "Excellence Initiative", supports the Cluster of Excellence "Engineering of Advanced Materials" (www.eam.uni-erlangen.de) at the University of Erlangen-Nuremberg. T.A. gratefully acknowledges DIKTI for a PhD scholarship. B.D. and Y.G. are supported by the Fluid Interface Reactions, Structures and Transport (FIRST) Center, an Energy Frontier Research Center funded by the U.S. Department of Energy, Office of Science, Office of Basic Energy Sciences.

\section{Supporting Information}

Supplementary data (schematic of synthesis set-up; details about electrode preparation; details about electrochemical testing; data on material characterization; data on electrochemical characterization) are available from Elsevier or from the author.

\section{References}

[1] B.E. Conway, Electrochemical Supercapacitor: Scientific Fundamental and Technological Application, 1st ed., Plenum Publishers, New York, 1999.

[2] J.R. Miller, P. Simon, Science 321 (2008) 651-652.

[3] M. Winter, R.J. Brodd, Chem. Rev. 104 (2004) 4245-4269.

[4] J.R. Miller, A.F. Burke, Electrochem. Soc. Interface 17 (2008) 53-57.

[5] P. Simon, Y. Gogotsi, Philos. Trans. R. Soc., A 368 (2010) 3457-3467.

[6] Y. Korenblit, A. Kajdos, W.C. West, M.C. Smart, E.J. Brandon, A. Kvit, J. Jagiello, G. Yushin, Adv. Funct. Mater. 22 (2012) 1655-1662.

[7] F. Beguin, V. Presser, A. Balducci, E. Frackowiak, Adv. Mater. 26 (2014) 2219-2251.

[8] J. Chmiola, G. Yushin, Y. Gogotsi, C. Portet, P. Simon, P.L. Taberna, Science 313 (2006) $1760-1763$. 
[9] K.L. Yang, S. Yiacoumi, C. Tsouris, J. Electroanal. Chem. 540 (2003) 159-167.

[10] J.K. McDonough, A.I. Frolov, V. Presser, J.J. Niu, C.H. Miller, T. Ubieto, M.V. Fedorov, Y. Gogotsi, Carbon 50 (2012) 3298-3309.

[11] B. You, J. Yang, Y.Q. Sun, Q.D. Su, Chem. Commun. 47 (2011) 12364-12366.

[12] M. Noked, S. Okashy, T. Zimrin, D. Aurbach, Angew. Chem., Int. Ed. 51 (2012) 1568 1571.

[13] Y. Chen, X. Zhang, H.T. Zhang, X.Z. Sun, D.C. Zhang, Y.W. Ma, RSC Adv. 2 (2012) 7747-7753.

[14] C. Portet, T. P.L., P. Simon, E. Flahaut, J. Power Sources 139 (2005) 371-378.

[15] Y. Gogotsi, A. Nikitin, H.H. Ye, W. Zhou, J.E. Fischer, B. Yi, H.C. Foley, M.W. Barsoum, Nat. Mater. 2 (2003) 591-594.

[16] A. Janes, L. Permann, M. Arulepp, E. Lust, Electrochem. Commun. 6 (2004) 313-318.

[17] I. Tallo, T. Thomberg, H. Kurig, K. Kontturi, A. Janes, E. Lust, Carbon 67 (2014) $607-$ 616.

[18] P. Becker, F. Glenk, M. Kormann, N. Popovska, B.J.M. Etzold, Chem. Eng. J. 159 (2010) 236-241.

[19] T. Knorr, F. Strobl, F. Glenk, B.J.M. Etzold, Chem. Eng. Technol. 35 (2012) 1495-1503.

[20] P.M. Vora, P. Gopu, M. Rosario-Canales, C.R. Perez, Y. Gogotsi, J.J. Santiago-Aviles, J.M. Kikkawa, Phys. Rev. B 84 (2011) 155114.

[21] T. Knorr, M. Kaiser, F. Glenk, B.J.M. Etzold, Chem. Eng. Sci. 69 (2012) 492-502.

[22] V. Presser, M. Heon, Y. Gogotsi, Adv. Funct. Mater. 21 (2011) 810-833.

[23] C. Largeot, C. Portet, J. Chmiola, P.L. Taberna, Y. Gogotsi, P. Simon, J. Am. Chem. Soc. 130 (2008) 2730-2731.

[24] G. Laudisio, R.K. Dash, J.P. Singer, G. Yushin, Y. Gogotsi, J.E. Fischer, Langmuir 22 (2006) 8945-8950. 
[25] B. Rufino, S. Mazerat, M. Couvrat, C. Lorrette, H. Maskrot, R. Pailler, Carbon 49 (2011) 3073-3083.

[26] M. Schmirler, F. Glenk, B.J.M. Etzold, Carbon 49 (2011) 3679-3686.

[27] G.Y. Gor, M. Thommes, K.A. Cychosz, A.V. Neimark, Carbon 50 (2012) 1583-1590.

[28] N. Shimodaira, A. Masui, J. Appl. Phys. 92 (2002) 902-909.

[29] J. Schwan, S. Ulrich, V. Batori, H. Ehrhardt, S.R.P. Silva, J. Appl. Phys. 80 (1996) 440447.

[30] R. Dash, J. Chmiola, G. Yushin, Y. Gogotsi, G. Laudisio, J. Singer, J. Fischer, S. Kucheyev, Carbon 44 (2006) 2489-2497.

[31] S. Urbonaite, J.M. Juarez-Galan, J. Leis, F. Rodriguez-Reinoso, G. Svensson, Microporous Mesoporous Mater. 113 (2008) 14-21.

[32] C.R. Perez, S.H. Yeon, J. Segalini, V. Presser, P.L. Taberna, P. Simon, Y. Gogotsi, Adv. Funct. Mater. 23 (2013) 1081-1089.

[33] K. Pinkert, M. Oschatz, L. Borchardt, M. Klose, M. Zier, W. Nickel, L. Giebeler, S. Oswald, S. Kaskel, J. Eckert, ACS Appl. Mater. Interfaces 6 (2014) 2922-2928.

[34] B. Dyatkin, Y. Gogotsi, Faraday Discuss. 172 (2014) 139-162. 
Table captions:

Table 1. Pore textural characteristics of core-shell and reference materials

Table 2. Electrical conductivity and resistance measured by 3 different methods 


\section{Figure captions:}

Fig. 1. Schematic of the core-shell porous particle.

Fig. 2. a) Cumulative pore size distribution derived from $\mathrm{N}_{2}$-sorption and QSDFT. b) Differential mass loss during temperature-programmed oxidation. c) TEM image of CDC shell on carbide core. d) SEM image of hollow core after burned amorphous part of CDCSTEP (color is used to highlight the shell and core).

Fig. 3. a) and b) $\mathrm{CV}$ measurement at 10 and $500 \mathrm{mV} \mathrm{s}^{-1}$. c) Capacitance normalized by specific surface area. d) Ragone plot of the core-shell and the reference materials.

Fig. 4. a) Galvanostatic charge-discharge at $1 \mathrm{~A} \mathrm{~g}^{-1}$ at whole voltage window and b) at around the vertex potential (current density of $1 \mathrm{~A} \mathrm{~g}^{-1}$ ). c) Nyquist plots (the inset: magnification in high frequency). d) Real part of capacitance normalized by capacitance at $10 \mathrm{mHz}$. 


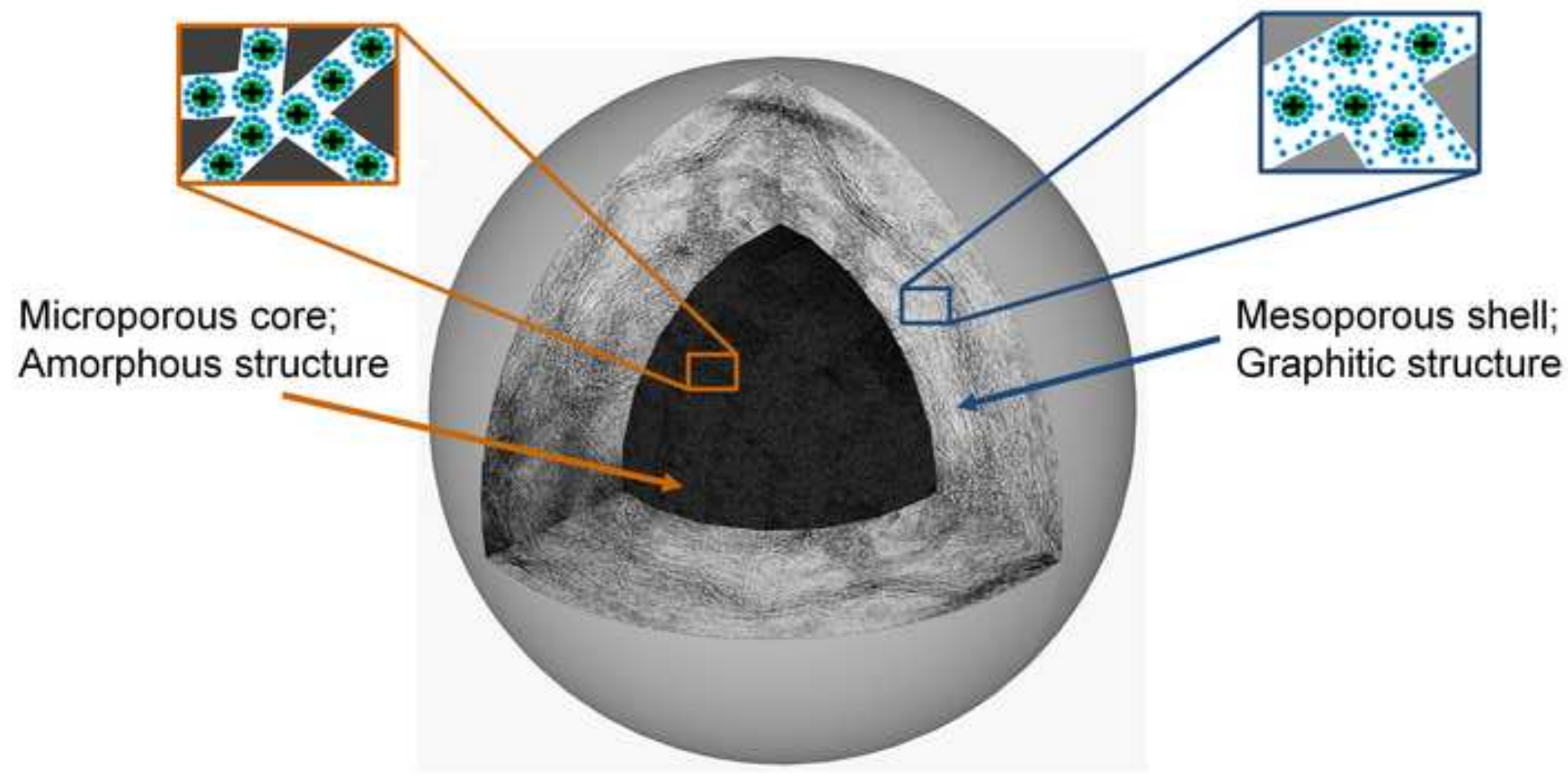

Microporous core; Amorphous structure

Mesoporous shell; Graphitic structure 

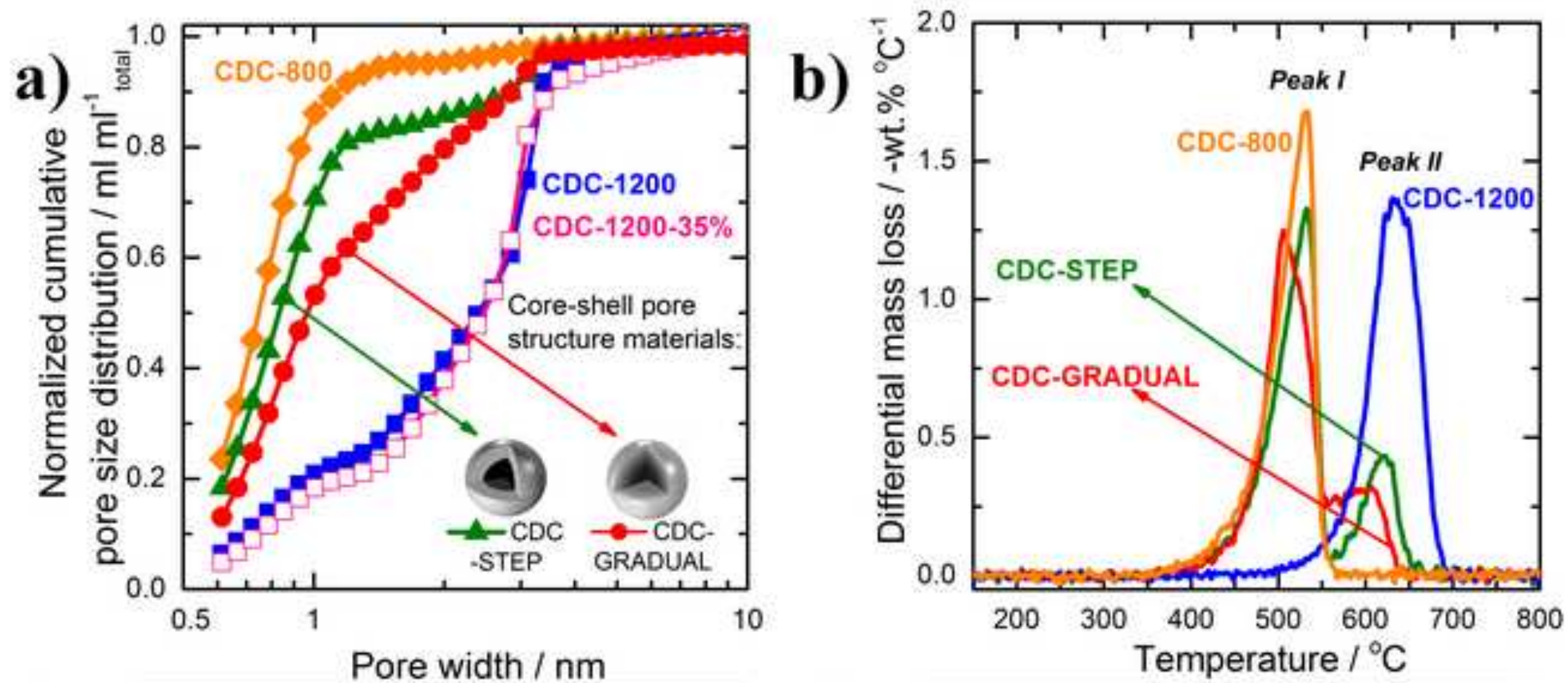

c)

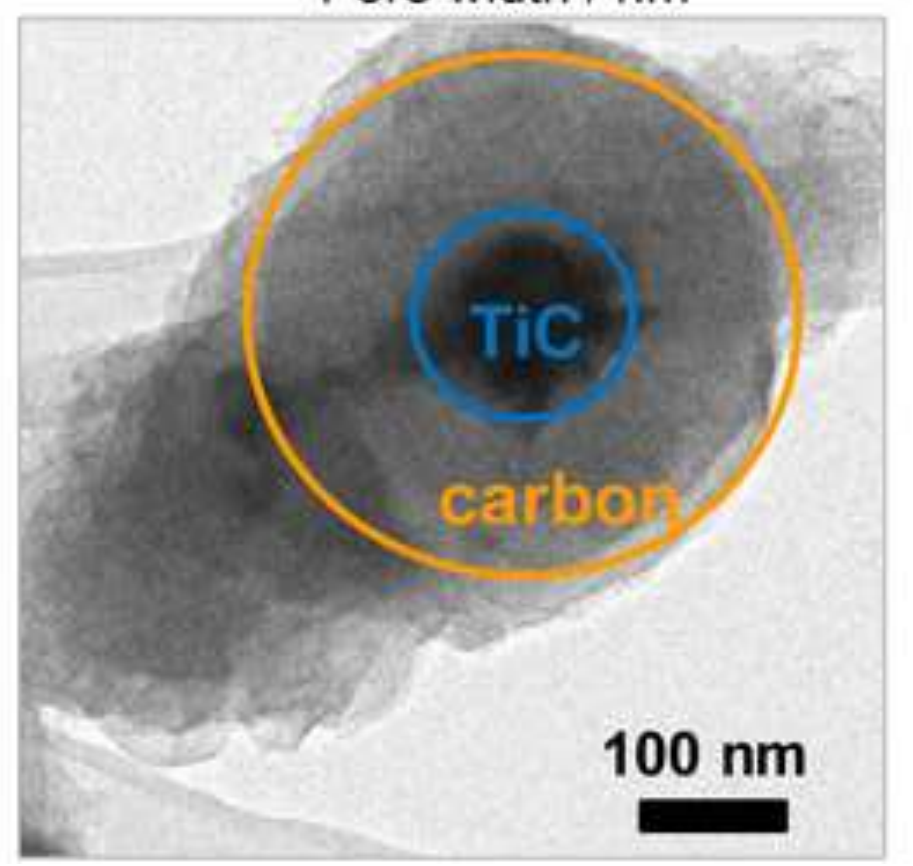

d)

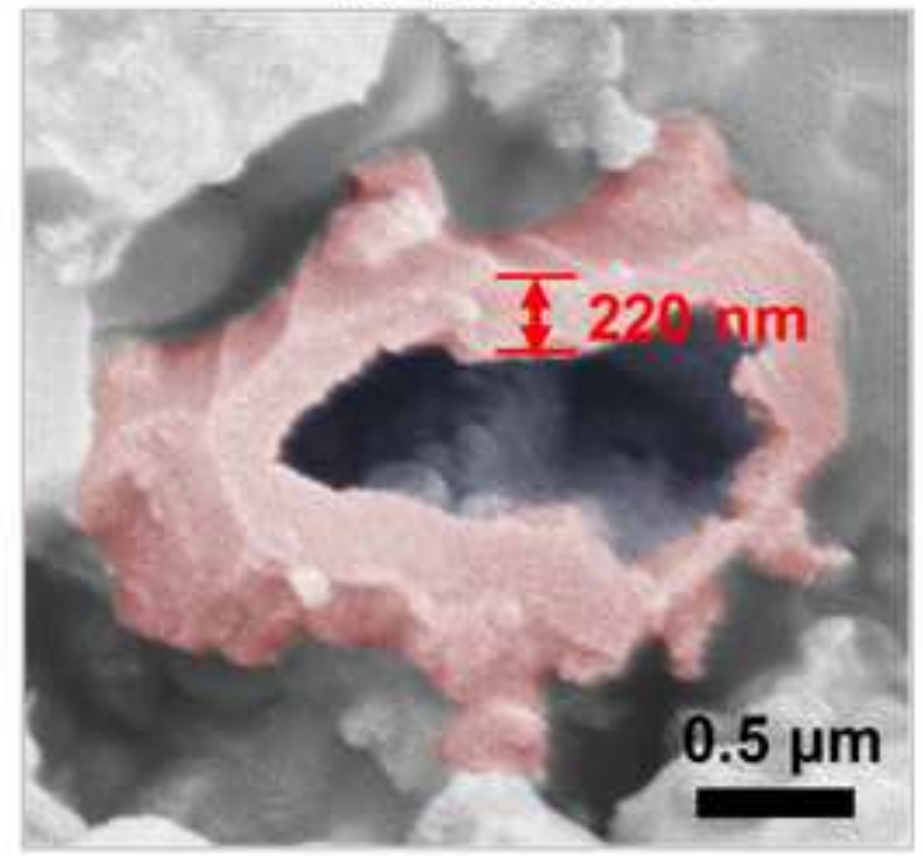


a)

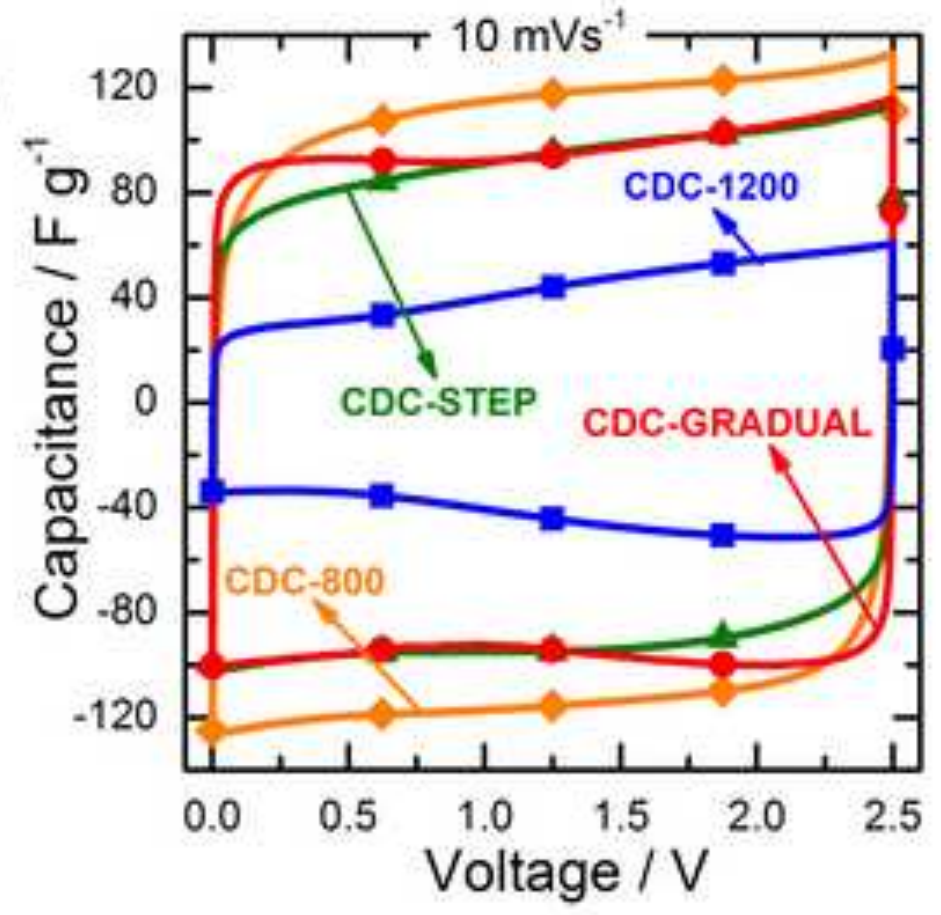

c)

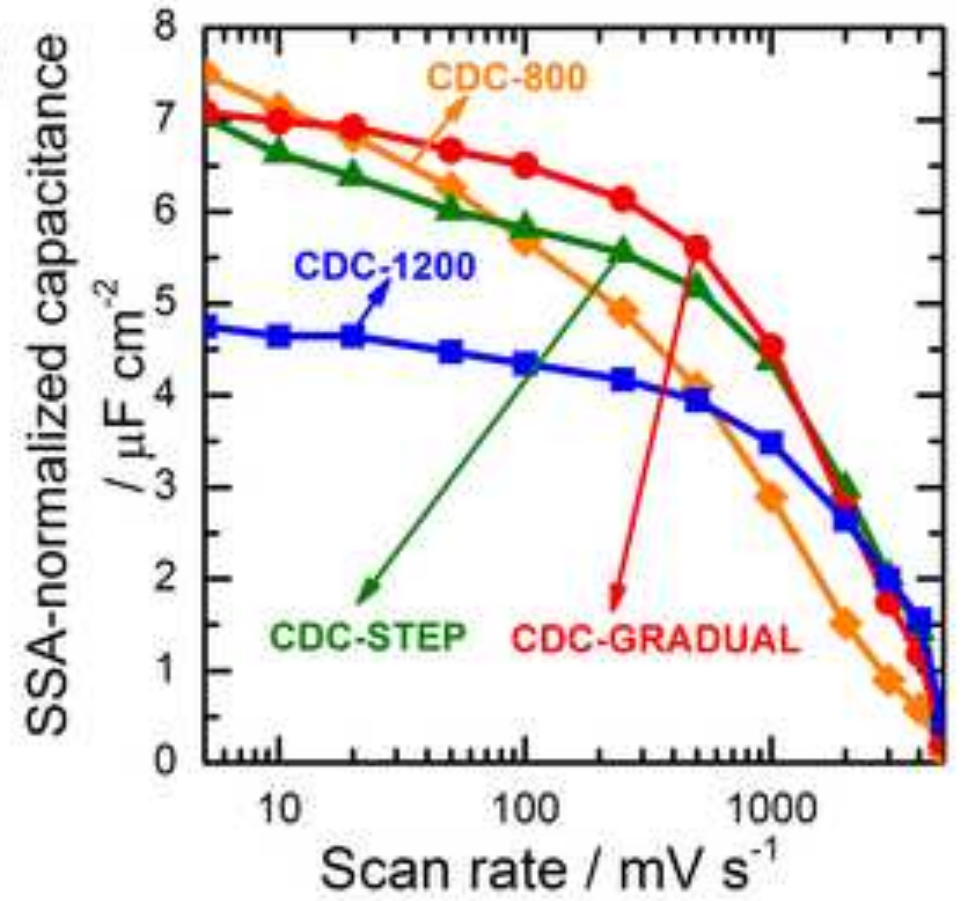

b)

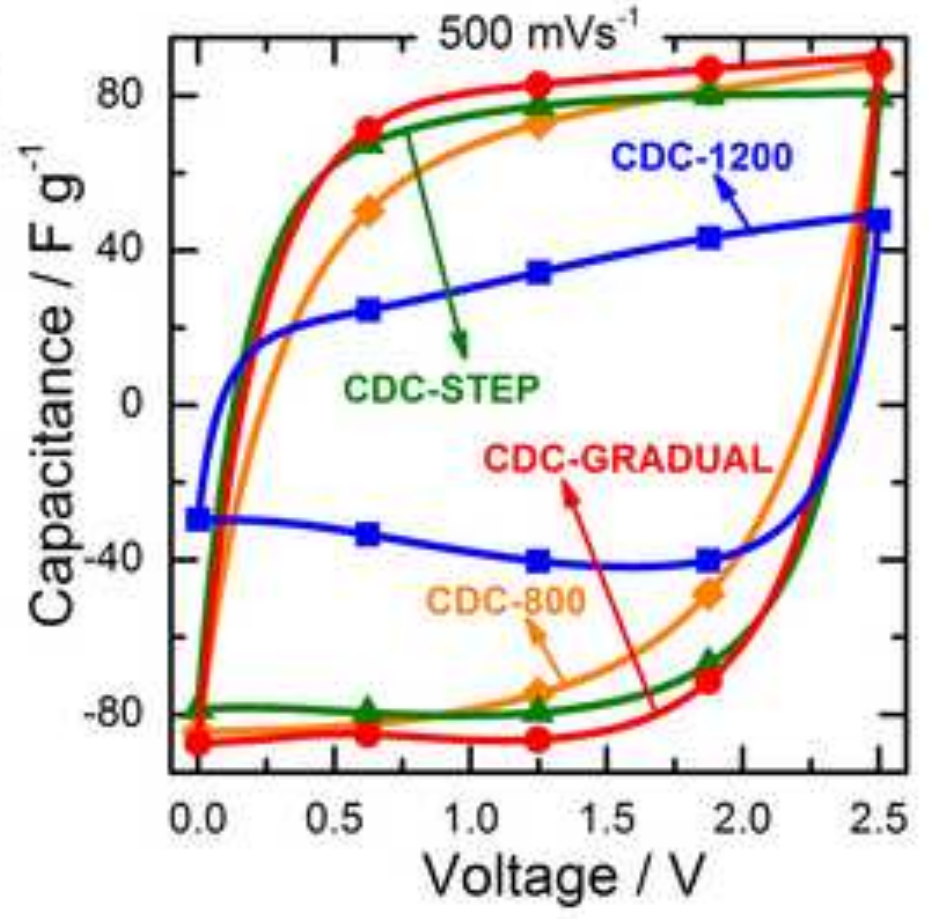

d)

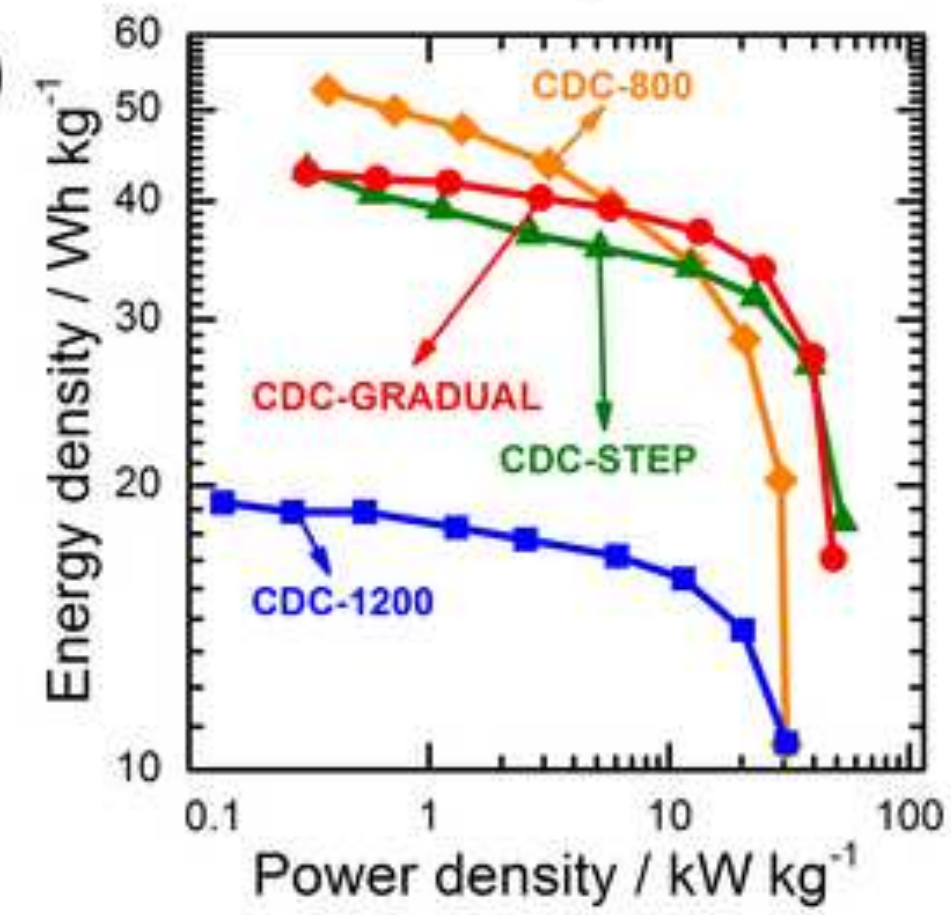



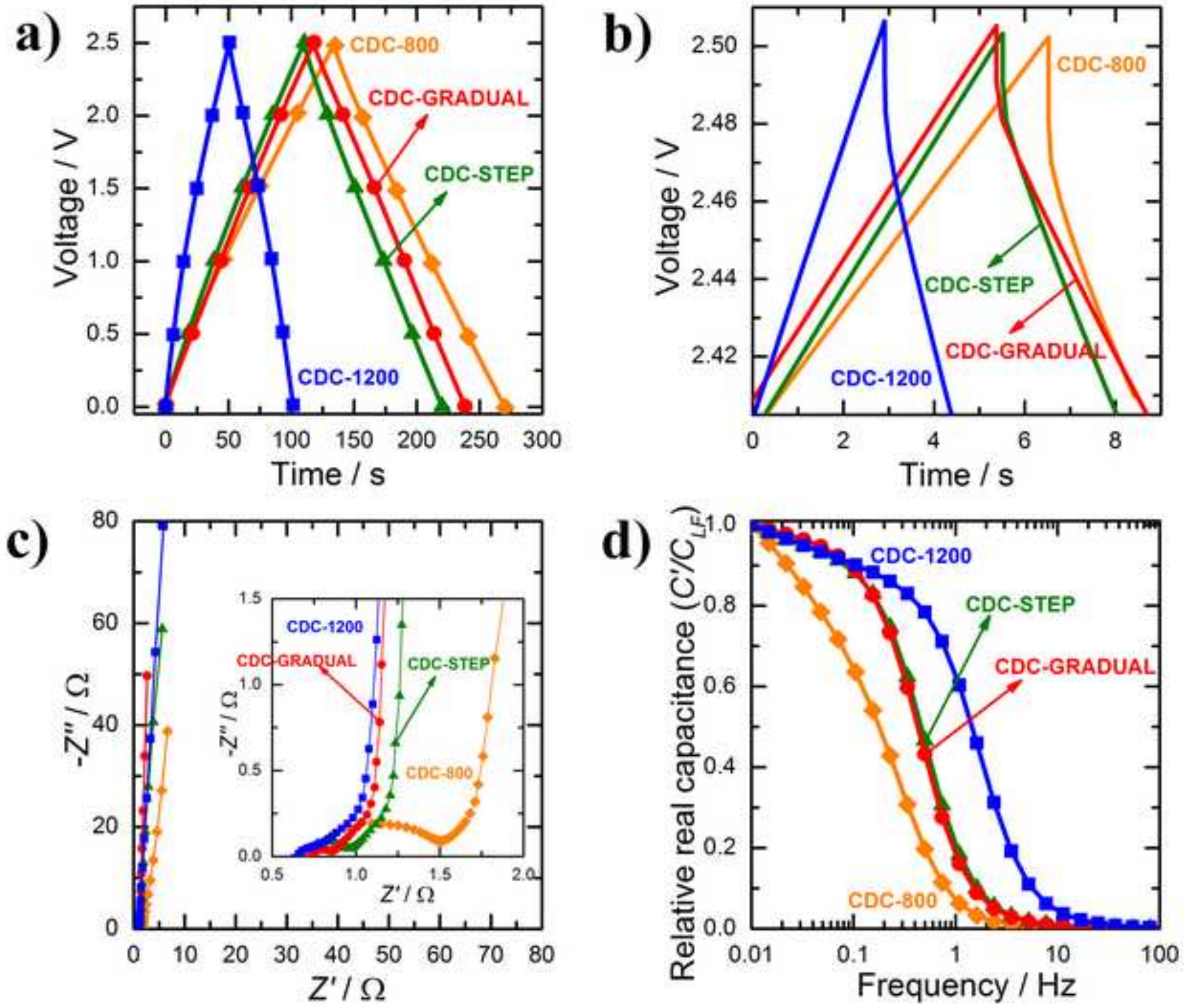
Table 1. Pore textural characteristics of core-shell and reference materials

\begin{tabular}{lllll}
\hline Material & $S S A^{\mathrm{a})} / \mathrm{m}^{2} \mathrm{~g}^{-1}$ & $V^{\mathrm{a})} / \mathrm{cm}^{3} \mathrm{~g}^{-1}$ & $V_{<1 \mathrm{~nm}}{ }^{\mathrm{b})} / \mathrm{cm}^{3} \mathrm{~g}^{-1}$ & $d_{v}{ }^{\mathrm{c})} / \mathrm{nm}$ \\
\hline CDC-1200 & 970 & 0.73 & 0.18 & 1.51 \\
CDC-STEP & 1490 & 0.65 & 0.46 & 0.87 \\
CDC-GRADUAL & 1510 & 0.76 & 0.41 & 1.01 \\
CDC-800 & 1540 & 0.61 & 0.53 & 0.79 \\
\hline
\end{tabular}

a) Specific surface area $(S S A)$ and pore volume $(V)$ were determined using the QSDFT slit-pore model

b) Subnanometer pore volume

c) Average slit-pore diameter, $\left(d_{v}\right)=2 V / S S A$ 
Table 2. Electrical conductivity and resistance measured by 3 different methods

\begin{tabular}{|c|c|c|c|c|c|}
\hline \multirow{2}{*}{ Material } & \multirow{2}{*}{$\begin{array}{l}\text { 4-point probe } \\
\text { method } \\
\text { Conductivity } \\
/ \mathrm{S} \mathrm{cm}^{-1}\end{array}$} & \multirow{2}{*}{$\begin{array}{l}\text { Galvanostatic } \\
\text { method } \\
\mathrm{R}_{\mathrm{SA}} \\
/ \Omega \mathrm{cm}^{2}\end{array}$} & \multicolumn{3}{|c|}{ EIS method } \\
\hline & & & $\begin{array}{l}\text { ESR } \\
/ \Omega\end{array}$ & $\begin{array}{l}\mathrm{R}_{\mathrm{ct}} \\
/ \Omega\end{array}$ & $\begin{array}{l}\text { Time constant } \\
/ \mathrm{s}\end{array}$ \\
\hline CDC-1200 & $2.72 \pm 0.14$ & 2.12 & 0.64 & 0.07 & 0.5 \\
\hline CDC-STEP & $1.50 \pm 0.12$ & 1.77 & 0.68 & 0.28 & 1.9 \\
\hline $\begin{array}{l}\text { CDC- } \\
\text { GRADUAL }\end{array}$ & $2.60 \pm 0.27$ & 1.60 & 0.71 & 0.15 & 2.1 \\
\hline CDC-800 & $0.15 \pm 0.02$ & 4.18 & 0.75 & 0.77 & 3.9 \\
\hline
\end{tabular}

